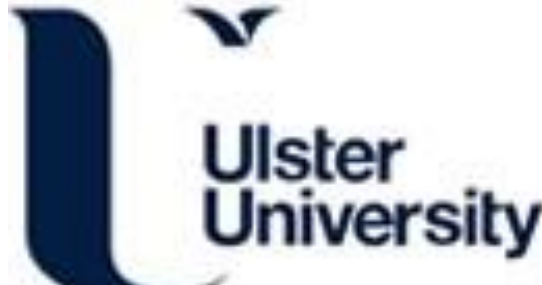

\section{Children Navigating Parental Cancer: Outcomes of a Psychosocial Intervention}

ONeill, C., O'Neill, C. S., \& Semple, C. (2019). Children Navigating Parental Cancer: Outcomes of a Psychosocial Intervention. Comprehensive Child and Adolescent Nursing, 43(2), 111-127. https://doi.org/10.1080/24694193.2019.1582727

Link to publication record in Ulster University Research Portal

\section{Published in:}

Comprehensive Child and Adolescent Nursing

\section{Publication Status:}

Published online: 15/03/2019

DOI:

10.1080/24694193.2019.1582727

\section{Document Version}

Author Accepted version

\section{General rights}

Copyright for the publications made accessible via Ulster University's Research Portal is retained by the author(s) and / or other copyright owners and it is a condition of accessing these publications that users recognise and abide by the legal requirements associated with these rights.

\section{Take down policy}

The Research Portal is Ulster University's institutional repository that provides access to Ulster's research outputs. Every effort has been made to ensure that content in the Research Portal does not infringe any person's rights, or applicable UK laws. If you discover content in the Research Portal that you believe breaches copyright or violates any law, please contact pure-support@ulster.ac.uk. 


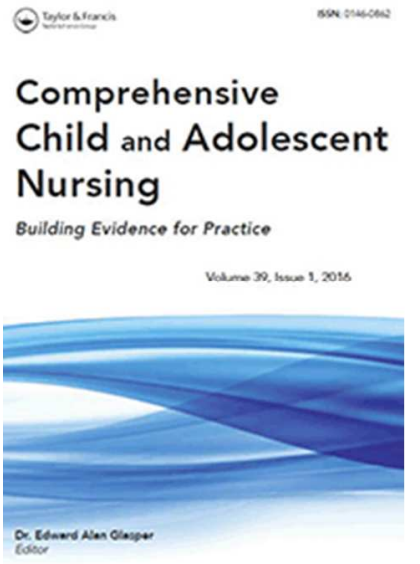

\section{Children navigating parental cancer: outcomes of a psychosocial intervention}

\begin{tabular}{|r|l|}
\hline Journal: & Comprehensive Child and Adolescent Nursing \\
\hline Manuscript ID & UCPN-2018-0022 \\
\hline Manuscript Type: & Original Papers \\
\hline Keywords: & $\begin{array}{l}\text { Parental cancer, Children, psychosocial intervention, family support, } \\
\text { Republic of Ireland }\end{array}$ \\
\hline \multicolumn{2}{|l}{} \\
\hline
\end{tabular}

\section{SCHOLARONE ${ }^{m}$}

Manuscripts 


\section{Title: Children navigating parental cancer: outcomes of a psychosocial intervention}

Keywords: Parental cancer, children, psychosocial intervention, family support, Republic of Ireland. 
Abstract

Research has evidenced a marked increase in the prevalence of cancer among younger people with up to one in five, parenting children under the age of 18 years of age. When a parent is diagnosed with cancer they experience fears and anxieties as they attempt to simultaneously manage their role as parent, with the illness experience. Parents have expressed difficulties in knowing how to communicate appropriately with their children throughout the illness trajectory as they are primarily focused on protecting or shielding their children from knowledge of the illness. Understandably parents may become overwhelmed with significant parental stress impacting on their psychological wellbeing. This subsequently effects the well-being of the entire family unit, coupled with changes to routines, roles and responsibilities. This study was carried out to examine how a group psychosocial intervention Children's Lives Include Moments of Bravery (CLIMB $\left.{ }^{\circledR}\right)$ helped young children to navigate parental cancer. A qualitative research design utilizing focus group methodology, artwork and individual interviews was used to generate data from 19 participants (parents, children and healthcare professionals). Three key themes emerged from the data, navigating the diagnosis, navigating emotions and changed routines, creating spaces to talk about cancer. The findings evidenced that attending CLIMB ${ }^{\circledR}$ was a positive experience for both children and parents. It gave the children the language and opportunity to express their fears and worries. CLIMB ${ }^{\circledR}$ equipped them with tools and skills to both express and manage their negative emotions, life skills that could be transferred to other challenging life events. All techniques that created spaces to talk and appeared to have a reassuring effect on the children. The parents appreciated the professional support that the structured intervention offered to them and helped them communicate more openly with their children. Creating spaces to talk about cancer reduces mistrust and tension between parents and children, when parental cancer occurs, and hopefully minimizes future psychological and social problems. 


\section{Introduction}

Over the past three decades there has been a marked increase in the prevalence of cancer among younger age groups, many of whom are parenting children. At any given time, up to one in five cancer patients are parenting children under the age of 18 years (Weaver, Rowland, Alfano, McNeel, 2010). In Ireland it is estimated that $15 \%$ of people with cancer are aged between 20-50 years (National Cancer Registry Ireland (NCRI, 2018). Changing demographics and increased survival rates of cancer patients present the additional probability that individuals who are faced with a cancer diagnosis will be caring for dependent children (Harris et al, 2009; Maddens et al., 2009).

Research has indicated that when a parent is diagnosed with cancer they face additional fears and anxieties as they attempt to simultaneously manage their role as parent, with their illness (Rauch \& Moore, 2010; Semple \& McCance, 2010a; O’Neill, McCaughan, Semple, Ryan, 2016). Parents have reported difficulties in knowing how to communicate appropriately with their children throughout the illness trajectory (O’Neill et al, 2016; Semple \& McCance, 2010a, 2010b) and they are primarily focused on protecting or shielding their children from the illness. Understandably parents can become overwhelmed and experience significant parental stress impacting on their psychological wellbeing, in some cases leading to depression (Kirsch, Brandt, Lewis, 2003; O’Neill et al., 2016). This has a subsequent effect on the entire family unit. When a parent is diagnosed with cancer the entire family undergo changes to routines, roles and responsibilities, all of which can cause huge disruption to both parents and children. (Scott et al., 2003).

There has been an increase in research on the impact of parental cancer on children over the last 20 years and findings have indicated that children are at an increased risk of psychological and social problems (Visser, Huizinga, Hoekstra, Hoekstra-Weebers, 2004; 
Osborn, 2007). These problems often differ depending on the age and gender of the child, and can include separation anxiety, depression, difficulties related to school, leisure, family functioning and relationships (Visser et al., 2004; Thastum et al., 2009). Certain attributes have been reported to facilitate adaptation to a parents' diagnosis. These include the parents own mental health status and ability to cope with the illness and family functioning, for example, parent-child communication (Su \& Ryan-Wenger, 2007; Thastum, Johansen, Gubba, Olesen, Romer, 2008; Krattenmacher et al., 2012). It is acknowledged that children require age appropriate information about their parents' cancer and they need support communicating with parents, family members and healthcare professionals (Semple \& McCaughan, 2013; Ellis, Wakefield, Antill, Burns, Patterson, 2016). Furthermore, children need an environment where they can feel comfortable discussing their emotions and have their experiences normalised among peers (Ellis et al., 2016).

Addressing the psychosocial impact parental cancer has on children has received attention through the development of interventions. In a recent systematic review of children's psychosocial needs and existing interventions, the evidence suggests that positive outcomes in relation to child and parental mood, child behaviour and communication can be achieved with interventions (Ellis et al., 2016). One such intervention which is delivered internationally is Children's Lives Include Moments of Bravery CLIMB ${ }^{\circledR}$. This is a 6-week group psychosocial intervention for children aged 5-12 years that was developed in Colorado in 2001. The background and details of which have previously been reported in the literature (Shallcross, Visvanathan, McCauley, Clay, van Dernoot, 2016; Semple \& McCaughan, 2013).

CLIMB ${ }^{\circledR}$ is delivered in over 35 locations in the Republic of Ireland (RoI) with over a 100 trained facilitators (see appendix 1). Despite the successful rollout of CLIMB ${ }^{\circledR}$ across the RoI, to date an evaluation has not being undertaken. Furthermore, although this psychosocial 
intervention is delivered internationally, to include many leading cancer units in the United States evaluation in peer-review literature has been limited (to the authors knowledge) to the studies of Shallcross et al, 2016; Semple \& McCaughan, 2013)

Although it may be the case that the programme is working satisfactorily, cognisance must be taken of different social and cultures contexts in the south of Ireland. Furthermore, it is essential that interventions are systematically evaluated to ensure they meet the needs of those availing of the service, thereby ensuring efficacy while also contributing to continued development and review of that service (Campbell et al., 2007). One must also be mindful of the need to ensure value for money is achieved for funders, given the current economic climate. Additionally, following the launch of the 2017 National Cancer Strategy (Department of Health, DoH) it has been identified that a comprehensive psycho-oncology and psychosocial support service plan should be developed, one that encompasses both the hospital and community care. CLIMB ${ }^{\circledR}$ is one intervention that has the potential to form part of the proposed model outlined in the strategy. 


\section{Method}

This aim of this study was to examine how a psychosocial intervention helped children to navigate parental cancer. A descriptive qualitative design was used. Focus groups were conducted with seven children by the first author in conjunction with the facilitator delivering the intervention. A topic guide based on current literature was used to focus the group discussion. At the beginning of the focus group the children were asked to write three words or draw three pictures describing what cancer meant to them. This technique has been shown to be developmentally appropriate as a means for children to demonstrate their understanding of illness (Guillemin, 2004).

In this study the drawings were used as supplementary data to the narrative data generated from the focus groups. The process of drawing allowed the children to visually demonstrate their knowledge of cancer and to visually display their experience of their parent's illness. Drawing also facilitated the children with a means of portraying their emotions, either simply or in a more complex way (Guillemin, 2004). This methodology was particularly suitable in this study as the children were already using this activity. Creative art therapy was one of the activities, in addition to play therapy that was employed in the psychosocial intervention sessions. As a rapport building exercise with the children the first author attended all of the programme sessions prior to data collection.

Concurrent focus groups were conducted with seven parents by the second author who has extensive experience in conducting qualitive data collection, in a separate room from the children. Similarly, a topic guide was used to lead the discussion. Interviews were also conducted by the first author with five facilitators delivering the psychosocial intervention to explore their experiences. Data was digitally recorded following informed consent. 
The inclusion criteria for this study included children aged 5-12 who were impacted by parental cancer, who had completed the 6-week CLIMB ${ }^{\circledR}$ programme and their parents following informed consent. Participants were recruited from two centres in the RoI. In addition to the children and parents, five facilitators were recruited who delivered the psychosocial intervention and had a professional health and social care background and had completed 2 days training in delivering the manualised CLIMB ${ }^{\circledR}$ programme. See table 1 for demographic details.

Ethical approval was sought from the Research Ethics Committee (REC) in Dublin City University prior to the research being conducted. To ensure that child assent and parental consent was obtained, detailed plain language statements and consent forms were developed that were age appropriate and in line with guidelines from the Department of Children and Youth Affairs (2012) and REC guidance. Additionally, to minimise distress, focus groups were conducted in the same location that the intervention was delivered and in a similar format to the previous intervention sessions. Arrangements were made for follow-up psychological support for participants if required. None of the participants required this additional support.

Data Analysis

Focus groups and individual interview data were transcribed verbatim. Data was analysed using Krueger's (2000) framework. Transcripts were read and reread line by line by the first and second authors. This data was initially coded and categorised thematically and following a critical discussion by both authors, final themes were generated. In addition, both authors, utilising Rose's framework (2007), engaged in a critical dialogue as part of the interpretation of the drawings produced by the children. The authors' interpretations were also guided by the children's focus group narrative data around the pictures. 
As part of the focus group the children were asked to write three words describing what cancer meant to them and to follow this up with a visual image. Some of the children integrated the images and the words, (see figure 1). All of the children were particular about their use of colour when constructing the images expressing how they needed the 'right' colour. Most of the children used dark colours such as black and dark blue in the pictures. Following the drawing exercise the children were asked to describe the drawings and what they meant to them.

The images were analysed using components of Rose's visual methodology framework (2007). The images signified terror, cancer as a monster, a nightmare, a tsunami, and spiders. All of the images, with the exception of one, were congruent with the focus group data. The image that differed both in content, form and colour was figure 2. This particular child (aged 11) first drew three very small images of what cancer meant to her; scared, a spider, and a monster. It is interesting that these smaller images were incongruent with the larger more colourful, delicate image of 'the ghost of good will'. This particular child's parent had a secondary diagnosis of cancer. One could interpret this drawing as demonstrating the child's attempt to contain the fear she is experiencing. It seems that she appears to understand the gravity of her mother's illness. On the other hand, the image of the ghost could be interpreted as the child creating a preferred image; one that conveys a feeling of lightness and hope, and one that is more acceptable to her. In figure 3 the drawing represents cancer being killed by radiotherapy, with the smaller image on the left representing his mother being happy.

The findings from the parents, children and facilitators were compared and then woven together to present the narrative of how children navigated the experience of parental cancer. Three themes emerged from the convergent data, navigating the diagnosis, navigating emotions and changed routines, creating spaces to talk about cancer. 


\title{
Navigating the diagnosis
}

All of the parents were understandably devastated when they received their diagnosis, their everyday worlds were totally altered, and they were left without a map to navigate the uncertainty of the future. This uncertainty shaped the manner in which the children discovered that a parent had cancer. One of the children found out when she observed her Mother packing her bags and asked; 'why are you packing bags? Her mother replied, "I am going to the hospital because I have cancer" (C6: 8-year-old girl).

Some parents spent time and energy planning to tell the children about the diagnoses. One of the children recounted how he knew something was wrong when both parents arrived to pick him up from school:

\section{'I knew something was going to happen because that day my dad and my mum collected me from school and that's like really uncommon... it's always something bad when they both pick me up from school. I always think that'. (C 4: 10-year-old boy)}

\begin{abstract}
Another boy (C 7: 10-year-old) wondered why his father had sent a friend to pick him up from school that day. When he asked why this had occurred, his father told him that they were in the hospital for tests and they found out that his mum had cancer. Some of the children had prior experience of various relatives having cancer. One child in particular whom both sets of grandparents had died from cancer expressed that while he was shocked ' $I$ knew it was going to happen but then I didn't think it was actually going to happen, but it did' (C4, 10-year-old)
\end{abstract}

While some parents made plans and preparations to tell the children soon after diagnosis, other parents deliberated and pondered whether or not to tell their children the 'bad news' at a time they felt overwhelmed dealing with their own emotions. 
'We wanted to hide from the kids. We were just in kind of ... not in denial I would say but unsure of what to do, and where to go, and how to say anything, because of course we were just dealing with the shock of it' (P2)

As the parents struggled to come to terms with the diagnosis some of them became aware that the children, especially the older ones, sensed a change in the atmosphere at home. For many of the parents' surgery and or treatments commenced immediately following diagnosis. Thus, the parents had no choice but to give the children some explanation for hospital visits and in some cases hospitalisations. Agreement between partners on when to, what to and how to tell the children varied. Partners did not always agree on the timing of disclosure, as evidenced in the following excerpt;

'Going into a spin .... It was like we were both coiled up right beside the [Doctors] desk. Got the diagnosis, and then it was just pulled and the two spinning tops just went into a spin. And if you can imagine these two spinning tops, every time they touch anything it just goes flying, if they touch each other they go even worse, and so it took about probably, about 6 weeks or even longer for us to kind of reconnect. We were in two different worlds. And what happened then was there was an amount of distance and I couldn't understand, I couldn't assimilate the information, and I wasn't prepared to take any action with the children until I had assimilated it myself' (P3).

This demonstrates the unpreparedness parents felt which was further complicated when opposing views on disclosing the illness to the children occurred. The rapid nature in which diagnosis and treatment occurs gives little time and space for parents to process what is happening.

The children described how they hated the mention of the word cancer with some expressing how it scared, shocked, saddened and annoyed them. The children used visual images to help 
them describe what cancer represented to them. The images ranged from monsters, nightmares, clowns, and spiders. All of the things it seemed, that frightened them. The children represented these various images artistically (see figures 1-4). For many of the children, the term' cancer' was not new. They had heard it being used in relation to grandparent's illnesses and deaths; as well as extended family members such as aunts and family friends. Not all of the parents had explicitly told their children that they had cancer. In some instances this occurred only when the children attended the programme. One of the children articulated how she did not like using the term and how it affected her 'because it sort of disturbs me, because it makes me feel funny, so I can't really focus' (C6: 8-year-old girl)

Another child articulated the meanness of cancer and expressed how he did not like 'the way it acts to my mum, and I don't like her having it '(C5: 6 year old boy) Many of the children were emotional when recounting how they learned about a parent's illness and they also displayed emotion and empathy when hearing the other children in the group talk about their own experiences.

\section{Navigating emotions and changed routines}

Attending the programme gave all the children emotional support and conceptual knowledge about cancer and the treatments involved. Meeting others in the same predicament helped them and appeared to have a reassuring effect. One of the boys expressed that attending enabled him to gain a better understanding of cancer and related treatment which reduced his anxiety:

'That we could talk about the sickness our mum's are having or our dad's and we could learn about it more and more to get less scared... I learned that cancer has two different treatments to try and get rid of it: chemo and radiotherapy. Chemo can pop good cells and 
bad cells, and radio [therapy] can pop just bad cells, and it focuses on one spot' (C7: 10year-old boy).

Whereas the following quote demonstrated how CLIMB ${ }^{\circledR}$ facilitated the expression of emotions;

if like one of your parents has cancer you should go to it [Climb $\left.{ }^{\circledR}\right]$ because you can like describe what you're feeling and tell them everything, like you don't really have to keep anything a secret because nobody is different to you there. 'Everybody [there] has parents who have cancer'... (C1: 11-year-old girl)

The use of arts and crafts helped the children express their emotions of anger and sadness and to articulate these emotions in dealing more effectively with their feelings. The worry box was a central device for the children in learning how to manage these feelings. The children used this tool to write a note about their worries and to keep this secretly in the worry box.

A second device was the anger cube, which was made in week 5, where the emotion being discussed was anger. The children drew pictures or wrote words of things that made them feel good or happy and placed these on each side of the cube. Then when the children were experiencing anger they threw the cube and used their own suggestions to modify these feelings. The success of the above strategies is evidenced in the data segment below: 'before [coming on the CLIMB ${ }^{\circledR}$ programme] I'm always in such a bad mood in the morning... on one of the pink ones [writing slips] I wrote down I were quite worried if my mam would die and stuff ... and I wrote down like when my mam was in hospital because it was really hard like' (C1: 11-year-old girl).

Another child expressed how the programme had helped him not to blame himself [for his father's cancer] and that he now discussed things with his older teenage sister and had told her about the activities and strategies he had learned. 
All of the children expressed feelings of sadness when they discovered their parent's illness and talked about how the illness had altered their daily routines. The overarching change in everyday life for the children was observing parental fatigue. This affected so many aspects of daily life and activities. For example, cooking meals changed from having full dinners to more simple dishes. One of the children expressed this:

'she's really tired and we don't cook as big meals so [we] just cook like pasta sometimes...she's always in bed and she always allows me on the computer when she's in bed but she never does that normally' (C4: boy 10year old)

Another child recounted how his father was always tired and spent all his time on the couch and when he 'puts a movie on he just falls asleep like [for] the whole movie' (C3: 11-yearold). For some of the children play dates were also curtailed because of parental fear of infections. Other children talked about how the fact of their parent's inability to drive affected their social activities. They were now using public transport or getting taxis and dependant on extended family and friends to take them to the various activities that children engaged in.

The data also evidenced that despite the activities on the programme many experienced heightened tensions in the home. They talked about quarrelling with other siblings and missed having one to one time with the ill parent.

'The girls (sisters) have been having time with mummy but I haven't. I don't really get to see mummy most of the time, because the cancer's stopping me' (C5: 6-year-old boy)

\section{Creating spaces to talk}

Meeting other children in similar situations helped somewhat normalise the illness experience. The children also learnt that they were not alone, they were not the only ones with a parent with cancer, and the isolation they experienced prior to coming on the 
programme dissipated. Having other children to talk to appeared to alleviate some of the anxiety for them. One facilitator described how peer support can be more important than what the facilitator has to offer, and in this way the group support can be very powerful among the children.

'so they're all kind of going through a similar experience and they hopefully then listen to each other a little bit because it's way more important to what ... I always feel the things that they say out loud in the group are way more important than anything I'll ever say in the group' (F2)

The children are also learning about cancer and the different treatments that their parents are going through in an age appropriate manner and in a language that they can understand through art or games. The programme also provides the children with tools to deal with their emotions, which are akin to life skills, and these can be shared with other siblings and their parents. Facilitators also acknowledged that these tools can help the children to better communicate with their parents and the facilitators while engaging in a fun art activity. 'It's very hard for kids to talk to adults, particularly when in $90 \%$ of the homes the adults won't talk to each other. So, I think the little tools help them communicate with adults. (F5) The CLIMB ${ }^{\circledR}$ programme repositions the children at the centre of the family once more, a position they held prior to the cancer diagnosis;

'I think actually the number one thing for me is they (children) become an important person again. And I don't mean they're forgotten about in homes at all. I mean, the child will still be in it. But at the end of the day, all of a sudden, the visitors who came to see them aren't coming to see them anymore. So, they come into a room and it's all about them. It's not about anybody else. It's about them' (F5).

Children are also better informed about their parent's cancer and better equipped to deal with their feelings. The programme can also give the children the confidence to ask difficult 
questions they may not have felt they could have previously asked. Children are now involved in the illness journey.

Facilitators described how frequently parents are afraid to talk to their children about cancer. Parents value the professional support that the programme offers in commencing this dialogue. The facilitators also described how frequently parents are desperate to do something to help their children develop an understanding of the illness. Enrolling the children on the CLIMB ${ }^{\circledR}$ programme makes them feel that they are doing something positive and useful for their children. Often cancer treatment regimens and schedules result in some parents feeling they do not have the space or time to give to their child but the programme creates and offers that space so that the children can talk about their worries and concerns. This is a relief and somewhat creates a respite for parents as it also provides space for the parents to process their own worries and uncertainties. 


\section{Discussion}

The findings from the study showed that a cancer diagnosis in a family is a devastating event for the entire unit. Parents understandably were shocked with some needing time to process the information before they could think about discussing it with their children. The timing of the disclosure to the children varied amongst the parents in this study. Some depending on their level of self-awareness and emotional intelligence began this conversation at an early stage while on the other hand, many of the parents felt ill-equipped to deal with the emotionality around the word cancer. Findings that concur with what is already known about parents' responses to a diagnosis (Raunch and Moore., 2010; Semple and McCance 2010a). This finding supports the benefits of having timely conversations with children to promote open communication and reduce mistrust, thus reducing the psychological and social problems that may arise, for both the children and parents (Visser et al., 2004; Osborn 2007).

The findings in this study evidence that parents were surprised at the ease at which the children adopted the language of the illness. They were not reticent about openly using the term 'cancer' and the programme helped them understand the various treatments and sideeffects that the parent with cancer was experiencing. However, despite the children's apparent ease with the language of cancer the images they drew demonstrated their fear, worries and of how their imaginations understood the illness.

Although the use of arts and crafts to facilitate the conversation and discussion with the children appeared to give them a certain level of comfort with the diagnostic language, their images demonstrated the reverse. Participating in the programme gave the children the words to articulate what was happening at home and they were now part of the illness conversation. While many of the parents did not disclose the diagnosis to the children at an early stage, the children sensed a change in the home environment. They knew that something was wrong. 
They intuited this change through the altered domestic routines, a finding that concurs with that of Scott et al., 2003; Semple \& McCaughan, 2013, and Furlong, 2017. Attending the CLIMB ${ }^{\circledR}$ programme was a positive step for all of the children. It gave them a chance to express their worries and meet other children in a similar situation, which appeared to have a somewhat reassuring effect as they bonded together as a community. This finding highlights the value of promoting a comfortable, normalised environment in which the children can talk to their peers (Ellis et al., 2016). The parents were aware of this also and felt that the programme removed some of the burden of responsibility on them. The tools the children learned to use on the programme were life skills that helped build resilience and could be applicable in any serious life event. In this study the tools were also used by other members of the family.

The findings from this study strongly evidenced that most of the children were better able to openly express their emotions and to use the adoptive strategies to manage their feelings.

One parent however, expressed a concern that his six year old child was displaying increased somatic symptoms since starting the programme. This father described how the child would internalise his emotions prior to starting the programme. However, he did acknowledge that the programme had given his son the words to express and process his emotions and this may have been a reason for his increased somatic symptoms. This one instance concurs with the findings of Shallcross et al., (2016) who suggest that when children gain a greater understanding of their emotions, a short-term increase of negative emotions may result from this insight. It is hoped that this will improve longer term positive adjustment into adulthood as previous studies (Visser et al., 2004; Osborn, 2007) have demonstrated that open communication with children surrounding parental cancer improved family cohesion with reduced requirement for psychological and psychiatric input in adulthood compared to those 
that had non-disclosure during childhood years (Huizinga, van der Graff, Visser, Dijkstra, Hoekstra-Weebers, 2003; Watson et al., 2006).

While the findings from this study align with those of Shallcross et al., (2016) and Semple \& McCaughan (2013) cognisance needs be paid to the challenges involved in delivering a programme that covers a broad age span. It may be that one to one sessions are necessary for children with significant distress as recommended in another psychosocial intervention (Phillips \& Prezio, 2016). This demonstrates the importance of facilitators being able to manage the different needs of the various children. A recommendation from the findings that an understanding that this may occur should be part of guidance information for parents and facilitators. Despite the differences between the children's level of emotional maturity and the disparity of ages, the parents and children unanimously agreed on the benefits of the programme. The parents felt that the strategies learnt on the programme empowered the children to manage their emotions, again a finding that concurs with other scholars (Shallcross et al., 2016; Semple \& McCaughan, 2013). The parents in turn felt empowered and better equipped to discuss and share the illness with their children and to include them in the illness conversation.

Another unexpected finding that emerged from the study was the differences between spouses on when to disclose information to their children about the cancer diagnosis. Some parents took longer to process the diagnosis resulting in disagreement around disclosure of information to the children. It has been noted in the literature that individuals' responses to illness may be influenced by their gender (O’Neill, McCaughan, Semple, Ryan, 2013). Although it has been acknowledged that men and woman can have similar cancer experiences, the manner in which men respond may be very different to women (Robertson, 2007). In addition, the changing patterns of family structures and relationships may make open communication more challenging (O’Neill et al., 2016). 
The findings in this study point to the importance of taking a family centred approach to talking about cancer with the children (Semple \& McCaughan, 2013; O’Neill et al., 2016; Turner, Clavarino, Yates, Hargraves, Connors, Hausmann, 2008). As previously mentioned there is no structured family support service available in the RoI. This is a wider policy issue that needs to be specifically addressed by the new Cancer Strategy which was published in 2017 by the Department of Health (DoH). There remains a significant gap in psychooncology and psycho-social support services with only two of the designated cancer centres having dedicated psycho-oncology services, one of which is part time $(\mathrm{DoH}$, 2017). Although a new proposed model which adopts a multi-disciplinary approach in the hospital and the community through cancer support centres is recommended, this proposal will require a co-ordinated and resource rich supports. As identified in the strategy, cognisance must be taken of the predicted growth in incidence of cancer and demand for services in the coming years, all of which will necessitate additional requirements to be added to current inadequate services $(\mathrm{DoH}, 2017)$. In conclusion, creating spaces to talk about cancer reduces mistrust and tension between parents and children when parental cancer occurs and hopefully minimises future psychological and social problems. This was a small study and the findings cannot be generalised. However, the authors argue that comparing the data from different groups in conjunction with the children's art work can enhance the strength of the research findings and can give the reader a richer understanding of the experiences and processes of the participants (Ritchie, Lewis, McNaughton Nicolls, Ormstom, 2014). Combining the collective voices of the children, parents and facilitators under three themes helped to give a richer conceptualisation of the children's experiences of parental cancer. Also, combining the collective voices clearly outlined the benefits of the group psychosocial intervention. 


\section{Acknowledgements}

The research team wish to extend their gratitude to all the children, parents and facilitators who took part in the study.

This study was funded by the fundraising initiative CLIMB4CLARE and the Ladies Gaelic Football Association.

\section{Declaration of Interest}

The authors report no conflicts of interest. 


\section{References}

Campbell, N. Murray, E. Darbyshire, J. Emery, J. Farmer, A. Griffiths, F. Guthrie, B. Lester, H. Wilson, P. \& Kinmonth AL. (2007). Designing and evaluating complex interventions to improve health care. British Medical Journal, 334 (7591):455-459.

Department of Children \& Youth Affairs. (2012). Guidance for developing ethical research projects involving children. Dublin: Department of Children \& Youth Affairs.

Department of Health. (2017). National Cancer Strategy 2017-2026. Dublin: Department of Health

Ellis, S.J. Wakefield, C.E. Antill, G. Burns, M. \& Patterson, P. (2016). Supporting children facing a parent's cancer diagnosis: a systematic review of children's psychosocial needs and existing interventions. European Journal of Cancer Care, E-publication ahead of print 18 Jan 2016.

Furlong, E. (2017). Protecting: A grounded theory study of younger children's experiences of coping with maternal cancer. Cancer Nursing, 40 (1), 13-21.

Guillemin, M. (2004). Understanding Illness: Using drawings as a research method. Qualitative Health Research, 14 (2), 272-289.

Harris, J., Bowen, D.J., Badr, H., Hannon, P., Hay, J. and Regan Sterba, K. (2009). Family communication during the cancer experience. Journal of Health Communication, 14 Suppl 1 76-84.

Huizinga, G.A., van der Graaf, W.T., Visser, A., Dijkstra, J.S. \& Hoekstra-Weebers, J.E. (2003). Psychosocial consequences for children of a parent with cancer: a pilot study. Cancer Nursing, 26, 195-202. 
Kirsch, S.E., Brandt, P.A. and Lewis, F.M. (2003). Making the Most of the Moment: When a Child's Mother Has Breast Cancer. Cancer Nursing, 26 (1), 47-54.

Krattenmacher, T., Kuhne, F., Ernst, J., Bergelt, C., Romer, G. and Moller, B. (2012).

Parental cancer: Factors associated with children's psychosocial adjustment- a systematic review. Journal of Psychosomatic Research, 72 (5), 344-356.

Krueger, RA. \& Casey, MA. (2000). Focus Groups: A Practical Guide for Applied Research (3rd ed.) CA: Thousand Oaks, Sage Publications.

Maddens, J., Brewster, D., Gavin, A., Steward, J., Elliott, J., Utley, M. and Moller, H. (2009). Cancer Prevalence in the United Kingdom: estimates for 2008. British Journal of Cancer, $101(3), 541-547$.

National Cancer Registry Ireland. (2018). Incidence Statistics. Available from: http://www.ncri.ie/data/incidence-statistics. Accessed June 2018.

O’Neill, C. McCaughan, E. Semple C.J. \& Ryan, A. (2016). Fathers' experiences of living with cancer: a phenomenological study. European Journal of Cancer Care, E-publication ahead of print 22 March 2016. DOI: 10.1111/ecc.12492

O’Neill, C. McCaughan, E. Semple C.J. \& Ryan, A. (2013). Fatherhood and Cancer: a commentary on the literature. European Journal of Cancer Care, 22 (2), 161-168.

Osborn, T. (2007). The psychosocial impact of parental cancer on children and adolescents: a systematic review. Psycho Oncology, 16 (2), 101-126.

Phillips, F. and Prezio, E. (2016). Wonders and Worries: evaluation of a child centred psychosocial intervention for families who have a parent/primary caregiver with cancer. Psycho-oncology, $8^{\text {th }}$ March, DOI: 10.1002/pon.4120. 
Rauch, P.K. and Moore, C. (2010). A Population-Based Estimate of Cancer Survivors Residing with Minor Children. Cancer, 116 (18), 4218-4220.

Robertson, S. (2007). Understanding Men and Health Masculinities, Identity and Well-being. Open University Press: Berkshire, UK.

Rose, G. (2007). Visual methodologies: an introduction to the interpretation of visual materials. 2nd ed. London: Sage Publications.

Ritchie, J. Lewis, J. McNaughton Nicolls, C. \& Ormstom, R. (2014). Qualitative research practice. London: Sage.

Scott, J.T. Prictor, M.J. Harmsen, M. Broom, A. Entwistle, V. Sowden, A. \& Watt, I. (2003). Interventions for improving communication with children and adolescents about a family member's cancer. Cochrane Database Systematic Reviews, 4: CD004511.

Semple, C.J. and McCance, T. (2010a). Experience of parents with head and neck cancer who are caring for young children. Journal of Advanced Nursing, 66 (6), 1280-1290.

Semple, C.J. and McCance, T. (2010b). Parents' experience of cancer who have young children: a literature review. Cancer Nursing, 33 (2), 110-118.

Semple, C.J. and McCaughan, E. (2013). Family life when a parent is diagnosed with cancer: impact of a psychosocial intervention for young children. European Journal of Cancer Care, $22(2), 219-231$.

Shallcross, A. Visvanathan, P. McCauley, R, Clay, A. van Dernoot, P. (2016). The effects of the CLIMB ${ }^{\circledR}$ on psycho-behavioural functioning and emotion regulation in children with a parent or caregiver with cancer: A pilot study. Journal of Psychosocial Oncology, 34 (4), $259-273$. 
Su, Y.H. \& Ryan-Wenger, N.A. (2007). Children's adjustment to parental cancer: a theoretical model development. Cancer Nursing, 30:362-381.

Thastum, M. Watson, M. Kienbacher, C. Piha, J. Steck, B. Zachariae, R. Baldus, C. \& Romer, G. (2009). Prevalence and predictors of emotional and behavioural functioning of children where a parent has cancer: a multinational study. Cancer, 115: 4030-4039.

Thastum, M. Johansen, M.B. Gubba, L. Olesen, L.B. \& Romer, G. (2008). Coping, social relations, and communication: a qualitative exploratory study of children of parents with cancer. Clinical Child Psychology and Psychiatry, 13, 123-138.

Turner, J., Clavarino, A., Yates, P., Hargraves, M., Connors, V., Hausmann, S. (2008). Enhancing the supportive care of parents with advanced cancer: development of a selfdirected educational manual. European Journal of Cancer, 44, 1625-1631.

Visser, A., Huizinga, G.A., van, d.G., Hoekstra, H.J. and Hoekstra-Weebers, J. (2004). The impact of parental cancer on children and the family: a review of the literature. Cancer Treatment Reviews, 30 (8), 683-694.

Watson, M., St James-Roberts, I., Ashley, S. Tilney, C., Brougham, B., Edwards, L., ...Romer, G. (2006). Factors associated with emotional and behavourial problems among school age children of breast cancer patients. British Journal of Cancer, 94, 43-50.

Weaver, K.E., Rowland, J.H., Alfano, C.M., and McNeel, T.S. (2010). Parental cancer and the family: A population-based estimate of the number of US cancer survivors residing with their minor children. Cancer, 116 (18), 4395-4401. 
Table 1; Participants demographics

\begin{tabular}{|c|c|c|c|c|}
\hline \multicolumn{5}{|c|}{ Children } \\
\hline ID & Age (yrs) & Gender & Parent with Cancer & Type of Cancer \\
\hline C1 & 11 & Female & Mother & Breast \\
\hline C2 & 8 & Female & Mother & Breast \\
\hline C3 & 11 & Male & Father & Colon \\
\hline C4 & 10 & Male & Mother & Breast \\
\hline C5 & 6 & Male & Mother & Breast \\
\hline C6 & 8 & Female & Mother & Breast \\
\hline C7 & 10 & Male & Mother & Breast \\
\hline
\end{tabular}

\begin{tabular}{|c|c|c|c|}
\hline \multicolumn{3}{|c|}{ Parents } \\
\hline ID & Gender & Cancer Yes/No & Type of Cancer \\
\hline P1 & Female & Yes & Breast \\
\hline P2 & Female & Yes & Breast \\
\hline P3 & Male & No & n/a \\
\hline P4 & Female & No & n/a \\
\hline P5 & Male & No & n/a \\
\hline P6 & Male & No & n/a \\
\hline P7 & Male & No & n/a \\
\hline
\end{tabular}


Appendix 1. Map of Centres Offering CLIMB ${ }^{\circledR}$

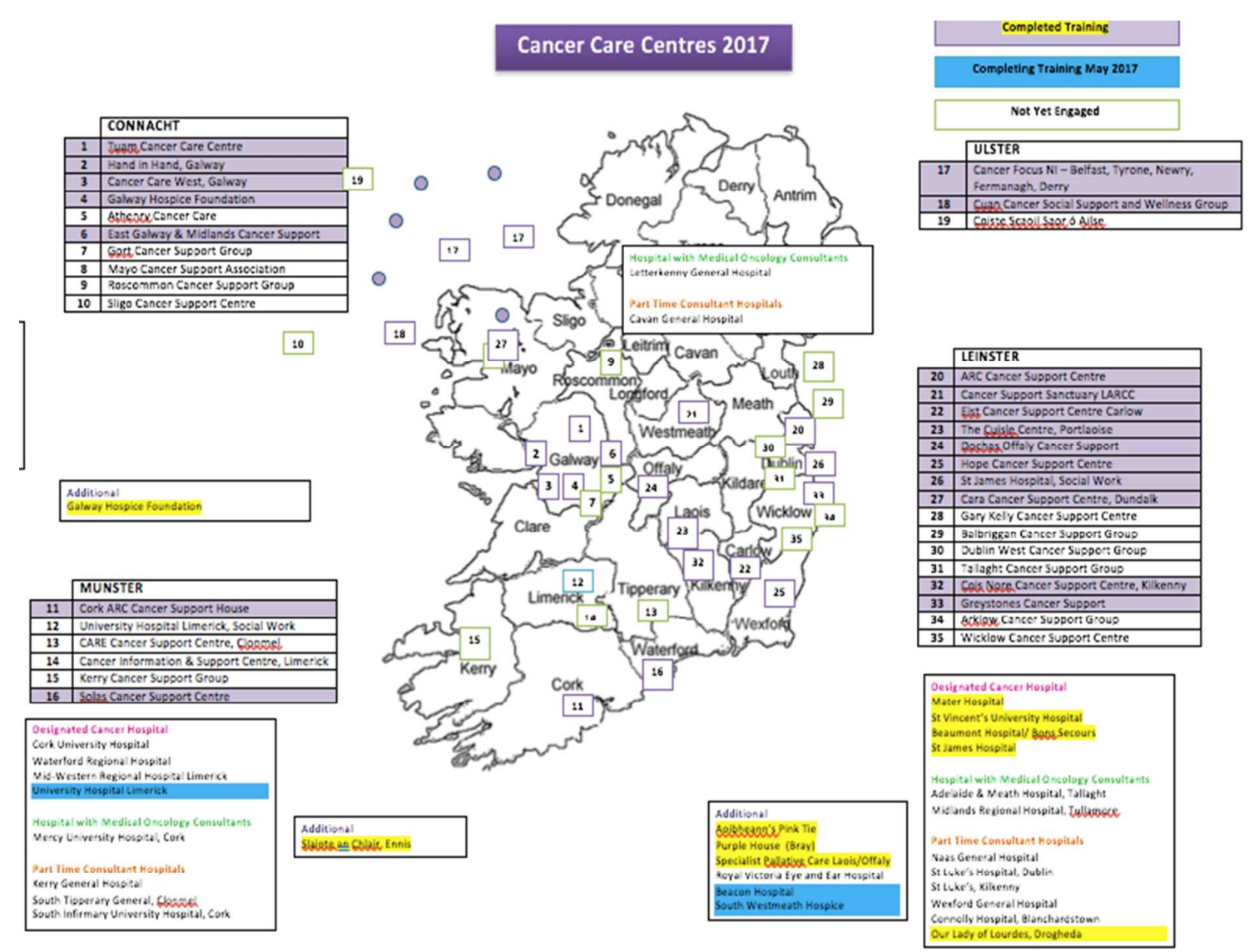

URL: http://mc.manuscriptcentral.com/ucpn Email: ICPN-peerreview@journals.tandf.co.uk 
Page 27 of 29

Comprehensive Child and Adolescent Nursing

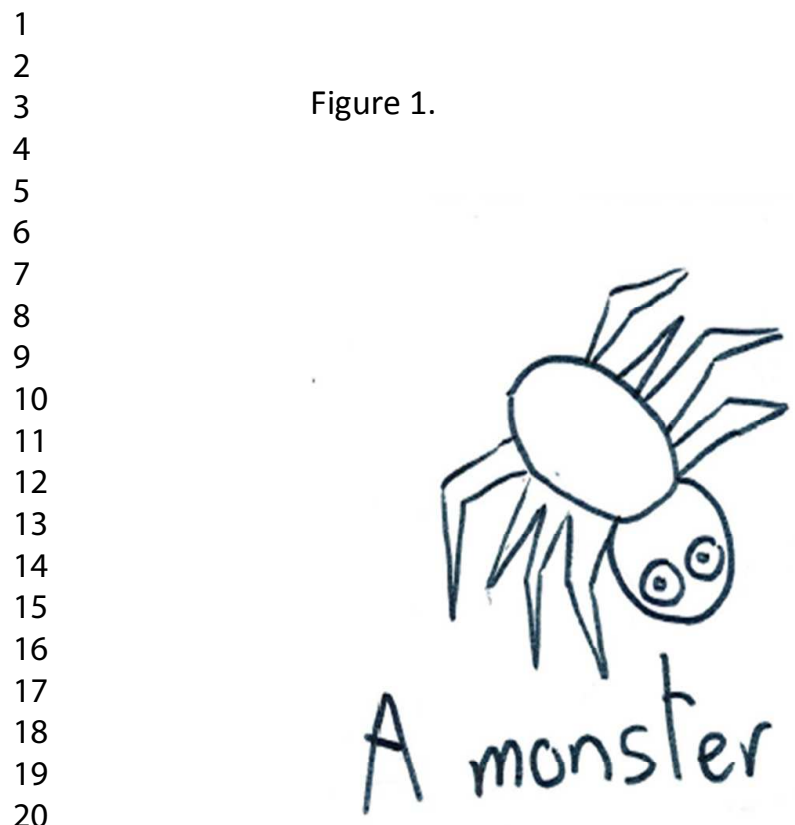

21

22

23

24

25

26

27

28

29

30

31

32

33

34

35

36

37

38

39

40

41

42

43

44

45

46

47

48

49

50

51

52

53

54

55

56

57

58

59

60

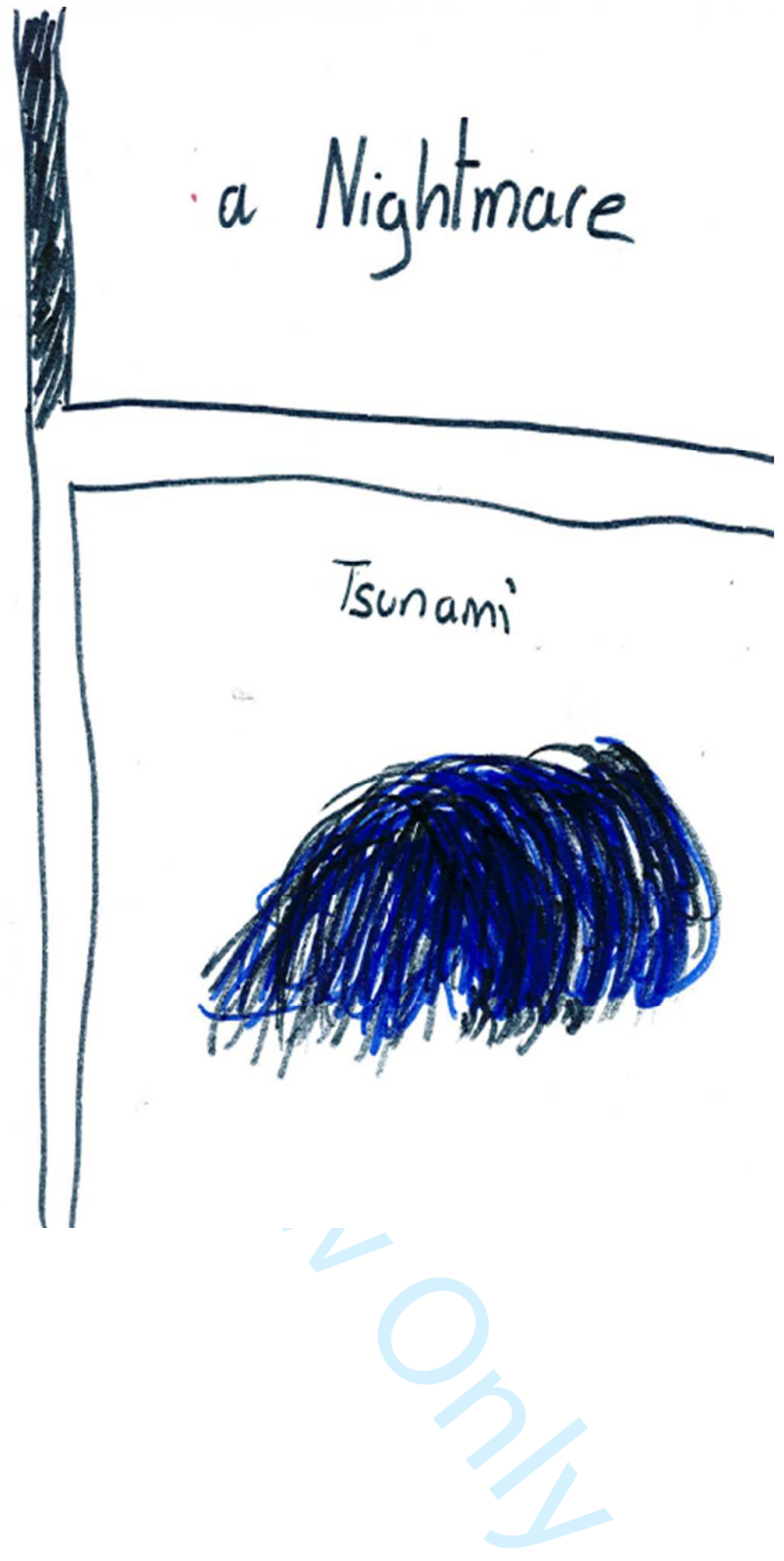

URL: http://mc.manuscriptcentral.com/ucpn Email: ICPN-peerreview@journals.tandf.co.uk 
Figure 2.
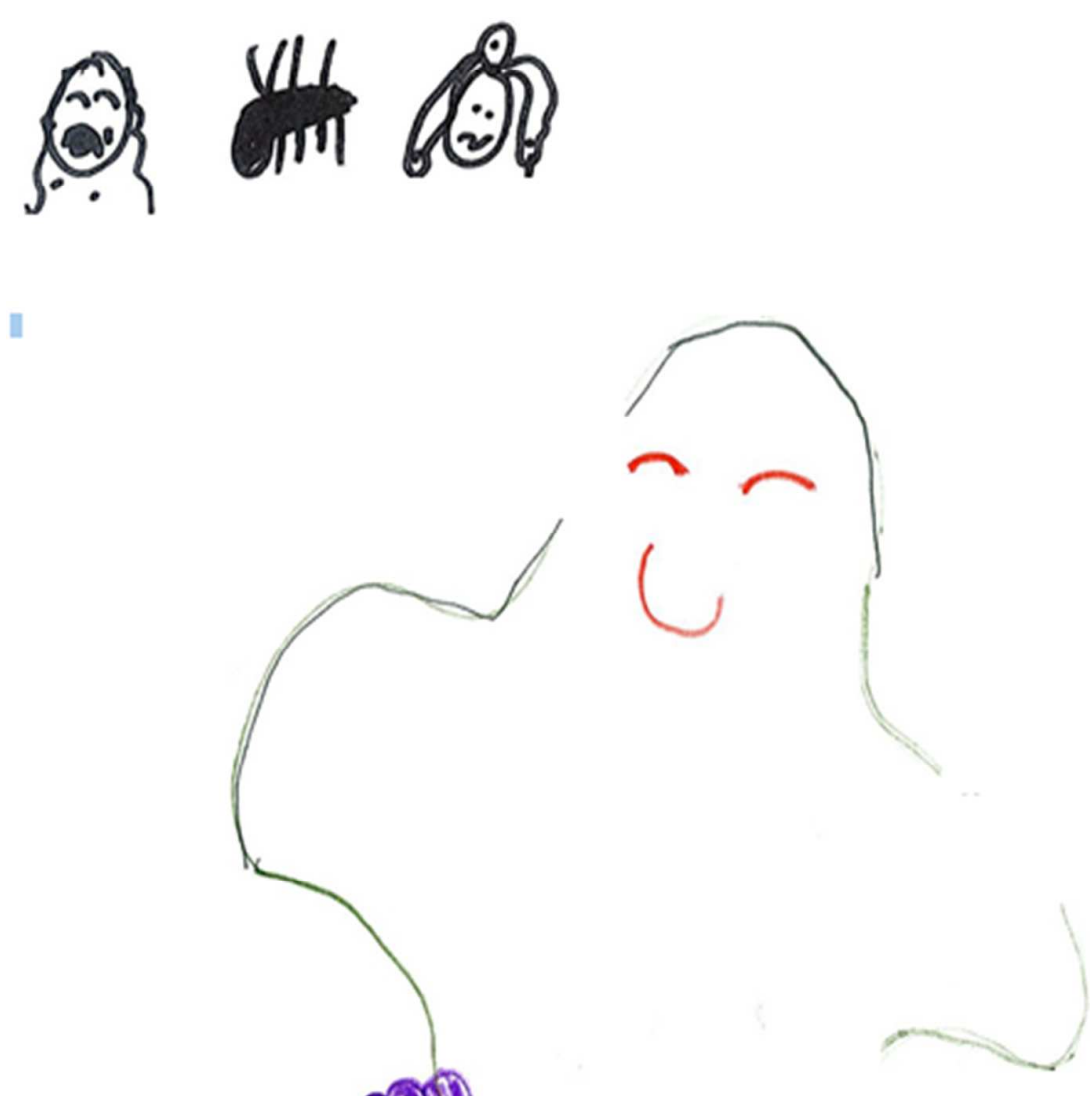
Figure 3.

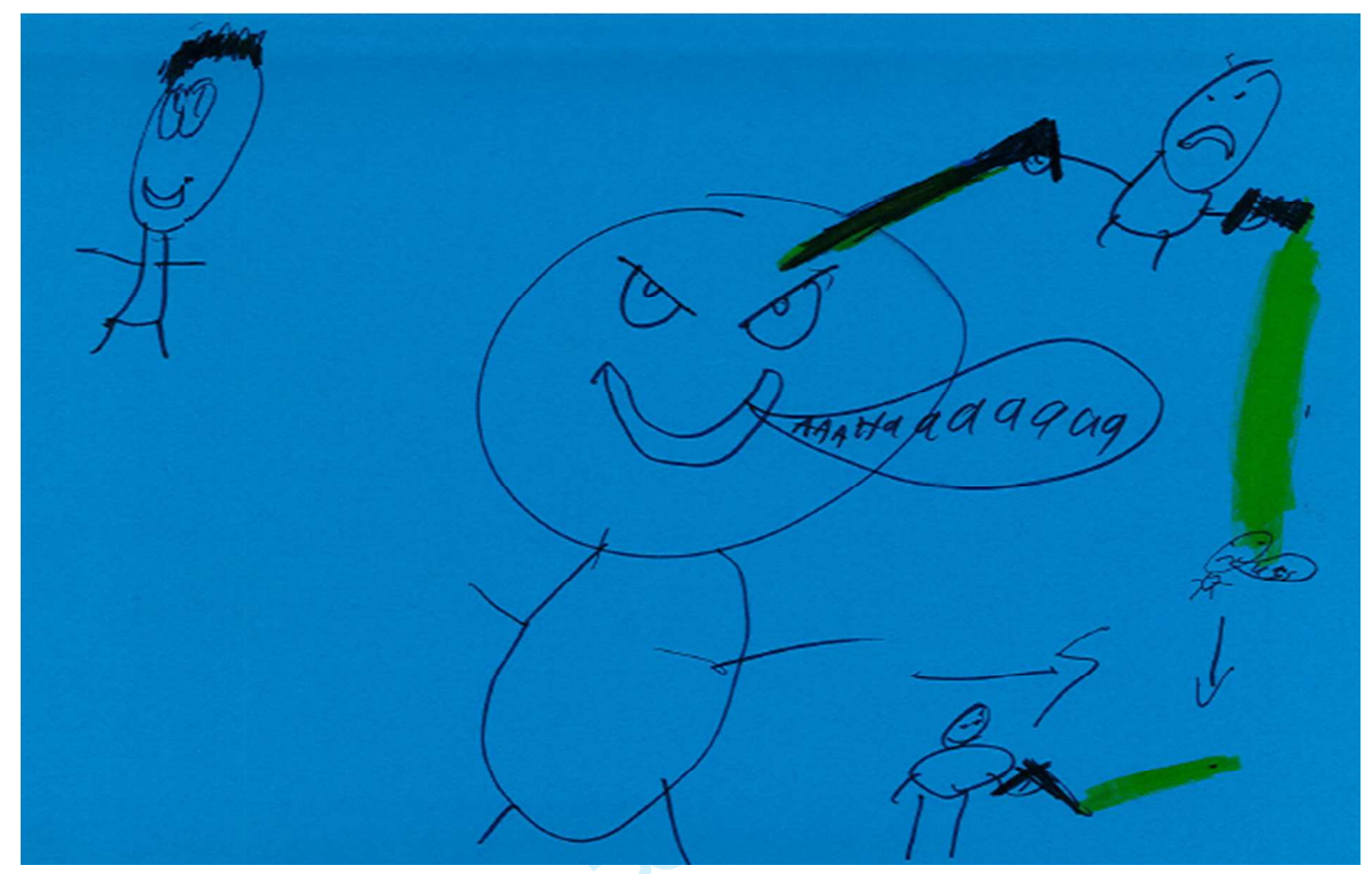

Figure 4.

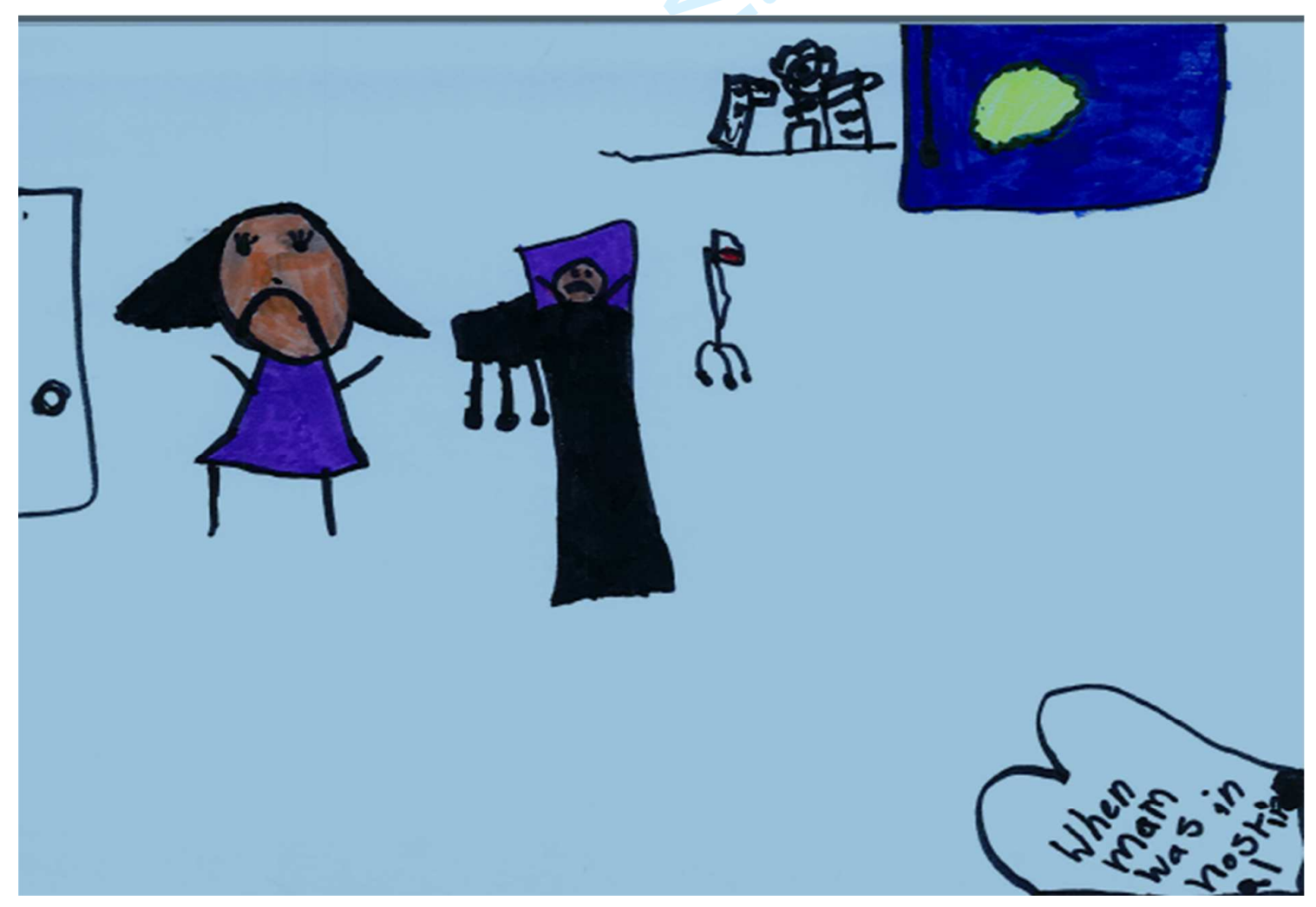

URL: http://mc.manuscriptcentral.com/ucpn Email: ICPN-peerreview@journals.tandf.co.uk 